\title{
Adolescents' perception of coercive treatment: conclusions and clinical implications Ingemar Engström
}

\author{
Address: Örebro University, Psychiatric Research Center, P.O. Box 1613, 70116 Örebro, Sweden \\ from WPA Thematic Conference. Coercive Treatment in Psychiatry: A Comprehensive Review \\ Dresden, Germany. 6-8 June 2007 \\ Published: 19 December 2007 \\ BMC Psychiatry 2007, 7(Suppl I):SI08 doi:10.II86/147I-244X-7-SI-SI08
}

This abstract is available from: http://www.biomedcentral.com/I47I-244X/7/SI/SI 08

(C) 2007 Engström; licensee BioMed Central Ltd.

\section{Background}

The aim of the study was to describe how involuntarily and voluntarily admitted adolescents talk about their experiences from child and adolescent psychiatric care with special focus on coercion, participation and dialogue.

\section{Methods}

Twenty-one adolescents, ten involuntarily and eleven voluntarily admitted, were interviewed in-depth. The transcriptions were analyzed based on theories on participation and human dialogue.

\section{Results}

The adolescents' experiences of coercion show a wide variation that didn't correspond very well with the formal situation. Coercion was experienced in many ways and was also valued quite differently with respect to the impact of the treatment in their lives. The adolescents' experience of participation in the planning of the treatment was very sparse. The requirements for participation of patients in Swedish law were seldom met, according to the adolescents. The adolescents' experiences of dialogue with the staff also varied considerably. Examples will be given from different experiences during the presentation.

\section{Conclusion}

Coercion is, from a subjective perspective, a concept with many meanings. The correspondence between formal coercion and experienced coercion is quite weak. Adolescents seldom feel genuinely engaged in the planning of their own treatment, despite legal requirements. Trustful and reciprocal relations were sometimes to be found in their stories. This seems difficult, but not impossible, to reach even under coercive circumstances. 